\title{
Evaluating Intercropping (Living Cover) and Mulching (Desiccated Cover) Practices for Increasing Millet Yields in Senegal
}

\author{
Patrick Trail,* Ozzie Abaye, Wade E. Thomason, Thomas L. Thompson, Fatou Gueye, \\ Ibrahima Diedhiou, Michel B. Diatta, and Abdoulaye Faye
}

\begin{abstract}
Located within the Sahel region, Senegal faces several agricultural production challenges. Limited rainfall, poor soil fertility, and insufficient agronomic inputs all contribute to low pearl millet [Pennisetum glaucum (L.) R. Br.] yields. This study was initiated to assess the potential for increasing millet yields through intercropping (living cover) and mulching (desiccated cover) practices. During the 2013 and 2014 growing seasons, pearl millet was intercropped with cowpea [Vigna unguiculata (L.) Walp.], mungbean [Vigna radiata (L.) Wilczek], or grown under mulch (neem [Azadirachta indica] leaves applied at $2 \mathrm{tha}^{-1}$ ). Field trials were conducted at two sites within Senegal's central milletpeanut (Arachis hypogaea L.) basin, in Bambey $\left(14^{\circ} 41^{\prime} 38^{\prime \prime} \mathrm{N}\right.$, $\left.16^{\circ} 28^{\prime} 12^{\prime \prime} \mathrm{W}\right)$ and Thiés $\left(14^{\circ} 45^{\prime} 45^{\prime \prime} \mathrm{N}, 16^{\circ} 53^{\prime} 14^{\prime \prime} \mathrm{W}\right)$. Soil moisture and plant $\mathrm{N}$ (based on the normalized difference vegetation index [NDVI]) were measured in addition to yield. When intercropped with a legume, millet grain yields increased up to $55 \%$ compared to millet alone. The combined grain yields under intercropping (millet + legume) were always higher than yields of millet alone, up to $67 \%$ in Bambey. Mulching increased soil moisture up to $14 \%$, with yield increases of up to $70 \%$ over millet with no mulch. Plant $\mathrm{N}$ increased in both intercropped and mulched millet, with NDVI increases up to $21 \%$ with mulch and $16 \%$ when grown with a legume (prior to flowering). These yield increases were achieved using resources that are available and affordable to small-scale producers in the region (seeds and mulch), and did not require the addition of fertilizer inputs.
\end{abstract}

\section{Core Ideas}

- Intercropping millet with cowpea or mungbean was found to increase millet grain yield compared to millet that was grown alone. Yield increases as high as 55\% were recorded.

- Increasing ground cover through mulching of millet was found to significantly increase soil moisture compared to millet grown with no additional ground cover. Soil moisture increased up to $14 \%$ in mulched soils compared to unmulched soils.

- Intercropping millet with a legume (cowpea or mungbean) always resulted in a higher combined yield than growing either the millet or the legume by itself.

Published in Agron. J. 108:1742-1752 (2016)

doi:10.2134/agronj2015.0422

Received 1 Sept. 2015

Accepted 23 Mar. 2016

Copyright (C) 2016 by the American Society of Agronomy

5585 Guilford Road, Madison, WI 53711 USA

All rights reserved
S ENEGAL is home to one of West Africa's most stable economies, but like many countries in the region it continues to struggle to provide the daily caloric needs of a growing population. The combination of population growth, small land holdings, inadequate agronomic inputs, and the environmental stresses of the region have combined to leave Senegalese smallholder farmers struggling to produce enough food. Located on the western edge of Africa's vast Sahel region, Senegal experiences some very harsh row-cropping conditions. Senegal's central millet-peanut basin has typically received between 250 and $750 \mathrm{~mm}$ of rainfall in a given year, and has a typical growing season (rainy season) of $90 \mathrm{~d}$ or less (Fussell et al., 1989). Poor soil fertility (Bationo et al., 1998), low waterholding capacity, and little to no organic matter (Fofana et al., 2008, Lahmar et al., 2012) are typical of the sandy soils found in this region of Senegal.

In response to these harsh conditions, many smallholder farmers in this region choose to cultivate a combination of drought tolerant crops that include pearl millet, sorghum [Sorghum bicolor (L.) Moench], cowpea, and peanut.

The most widely grown cereal crop in the region is pearl millet, which is well adapted to growing conditions not suited for other popular grain crops. It is well adapted for growing in soils that are too sandy, too dry, and too infertile for other grain crops such as maize (Zea mays L.) and sorghum (Stoskopf, 1985). Unfortunately millet in is not being produced at a rate high enough to support the general population, as Senegal remains a net importer of food (FAOSTAT, 2013). According to the United Nations Food and Agriculture Organization, Senegal yielded a yearly average of $770 \mathrm{~kg} \mathrm{ha}^{-1}$ of grain over the past $20 \mathrm{yr}$, compared to a West African average of $662 \mathrm{~kg} \mathrm{ha}^{-1}$ and an Indian average of $898 \mathrm{~kg} \mathrm{ha}^{-1}$ (FAOSTAT, 2013). More importantly, Senegal's pearl millet yield average has hardly improved since the 1970s while other crops such as rice (Oryza sativa L.), maize (Zea mays L.), and cassava (Manihot esculenta Crantz) have all experienced yield increases (FAOSTAT, 2013).

\footnotetext{
P. Trail, O. Abaye, W.E. Thomason, and T.L. Thompson, Virginia Polytechnic Institute \& State University (Virginia Tech) - Crop \& Soil Environmental Sciences, 330 Smyth Hall, 185 Ag Quad Lane, Blacksburg, VA 24061; F. Gueye, United States Agency for International Development - Education and Research in Senegal, BP 24690 Ouakam Rue 26 Ngor-Almadies, Dakar, Senegal; I. Diedhiou, Ecole Nationale Supérieure d'Agronomie - Department of Plant Pathology, University of Thiès, Thiès, Senegal; M.B. Diatta and A. Faye, Institut Supérieur de Formation Agricole et Rurale - Department of Plant Sciences, University of Thiès, Bambey, Senegal. *Corresponding author (ptrail12@vt.edu).
}

Abbreviations: LER, land equivalency ratio; NDVI, normalized difference vegetation index; VWC, volumetric water content. 
Table I. Monthly rainfall $(\mathrm{mm})$ and number of days receiving more than I $\mathrm{mm}$ of rainfall (DoR) between June and November for Bambey and Thiès in 2013 and 2014.

\begin{tabular}{rccccccccc}
\hline Year & Site & June & July & Aug. & Sept. & Oct. & Nov. & Total & DoR \\
\hline 2013 & Bambey & II & 133 & 302 & 153 & 39 & 0 & 638 & 41 \\
& Thiès & 0 & 49 & 369 & 26 & 21 & 0 & 465 & 24 \\
& & & & & & & & \\
\multirow{2}{*}{2014} & Bambey & 0 & 41 & 232 & 135 & 11 & 0 & 419 & 26 \\
& Thiès & 0 & 0 & 158 & 74 & 98 & 0 & 331 & 24 \\
\hline
\end{tabular}

In Senegal, pearl millet is considered a low-value crop grown for household consumption, and therefore does not receive the inputs (when available) that might be otherwise invested into cash-crops such as peanut or vegetables. There is a need to boost millet yields using means that are affordable and accessible to the average smallholder farmer of Senegal's central millet-peanut basin. Production practices that have the potential to increase millet yields and build soil health without the introduction of expensive resources could prove critical in this region (Lahmar et al., 2012; Schlecht et al., 2006). Practices that encourage crop diversity and the maintenance or introduction of continuous ground cover could be particularly valuable in boosting long-term millet yields.

Many practices adhering to these principles have been present for many years in Senegal and the Sahel, while other practices have been introduced in recent years. Planting crops in association or in rotation are both traditional practices in the Sahel (Schlecht et al., 2006), while maintaining crop residues or soil cover have been more recently introduced. Though not as common as traditional rotational systems, cereal-legume intercropping systems already play an important role in the region for enhancing food security (Diangar et al., 2004). Millet-cowpea intercropping is one of the combinations most widely practiced in the region and is often adopted as an "insurance" tactic, allowing farmers to spread the risk of crop failure across two crops (Bationo and Ntare, 2000). Crop residue management is less common, but has been encouraged over traditional practices of post-season burning (Bationo et al., 1998). Its adoption has been slow, but is not an entirely foreign concept. For the purposes of this study intercropping and mulching practices were both selected for their varying abilities to provide continuous organic soil cover and to individually improve yields in different ways; legume intercropping through $\mathrm{N}_{2}$ fixation, and mulching for soil moisture conservation purposes.

Several studies have been performed throughout West Africa and the Sahel addressing intercropping and mulching practices separately and their effects on millet yields (Buerkert et al., 2000; Diangar et al., 2004; Lahmar et al., 2012; Ntare, 1990; Reddy et al., 1992). Nitrogen recovery and transfer has been studied in Senegal (Sarr et al., 2008), and Niger (Laberge and Haussmann, 2011) in millet-cowpea intercropping systems, while soil moisture conservation in millet production has been identified from crop residue retention (Rebafka et al., 1994), mulched-based systems (Buerkert et al., 2000) and legume intercropping systems (Grema and Hess, 1994; Zegada-Lizarazu et al., 2005). There has not been however, adequate comparative research to distinguish the role of soil moisture conservation or $\mathrm{N}$ addition in each of these two separate practices. Our work aims to better understand these practices and the particular services they each provide to the primary cereal crop.
During the 2013 and 2014 growing seasons, field studies were conducted at two locations in central Senegal to assess the potential for improving pearl millet yields without use of fertilizers or irrigation. The overall aim of this study was to assess the potential for increasing millet yields through the introduction of ground cover, either living and productive (intercropping) or desiccated (mulch). Specific objectives of our study were to quantify and evaluate (i) increases in ground cover provided by intercropping and mulching; (ii) the effect of an additional crop on millet yields grown in the same field in the same season; (iii) soil moisture conservation under intercropping and mulching practices; (iv) $\mathrm{N}$ in intercropped millet vs. millet grown alone; and (v) mungbean as an alternative food legume to cowpea in millet-legume intercropping systems.

\section{MATERIALS AND METHODS}

\section{Site Descriptions}

Field studies were located at two sites within Senegal's central millet-peanut basin, near the towns of Bambey $\left(14^{\circ} 41^{\prime} 38^{\prime \prime} \mathrm{N}\right.$, $\left.16^{\circ} 28^{\prime} 12^{\prime \prime} \mathrm{W}\right)$ and Thiès $\left(14^{\circ} 45^{\prime} 5^{\prime \prime} \mathrm{N}, 16^{\circ} 53^{\prime} 14^{\prime \prime} \mathrm{W}\right)$. Climate in this region is characterized by a short unimodal rainy season that typically occurs between June and October, and receives an average of $400 \mathrm{~mm}$ of rainfall each year (Climate Research Unit of East Anglia, 2014). Table 1 summarizes rainfall during the 2013 and 2014 growing seasons at each of the two sites. The rainy season in 2014 arrived a full month later than in 2013 and rainfall amounts were lower. Soils at each site are typical of the region, and pertinent soil characteristics for each site are summarized in Table 2.

\section{Experimental Design}

The experiment consisted of eight treatments arranged in a randomized complete block design with four replications (blocks). Millet was grown alone in the first treatment, according to local practice, as the control. The following treatments included two morphologically diverse cultivars of cowpea (one upright and one viney), and one cultivar of mungbean; each grown alone and each intercropped with millet (Table 3). Millet was also grown alone with mulch (neem leaves applied at $2 \mathrm{t} \mathrm{ha}^{-1}$ of dry matter). Neem was selected as an appropriate mulch due to its abundance and local availability throughout Senegal; it has also shown potential as an effective mulch in terms of nutrient content and soil moisture conservation (Tilander and Bonzi, 1997). Treatments are summarized in Table 3. Individual plots measured 4 by $4 \mathrm{~m}$. Millet was planted in hills and thinned to three plants per hill; hills were spaced 1 by $1 \mathrm{~m}$ with hill densities of 10,000 hill per hectare, representative of local millet production practices. Legumes were planted at 0.5 by $0.5 \mathrm{~m}$ and thinned to one plant. Plant densities were 40,000 hills per hectare for legumes grown alone 
Table 2. Summary of soil physical and chemical properties at Bambey and Thiès sites.

\begin{tabular}{|c|c|c|c|c|c|c|}
\hline \multirow[b]{2}{*}{ Site } & \multirow[b]{2}{*}{$\mathrm{pH} \dagger$} & \multirow{2}{*}{$\begin{array}{l}\text { Organic } \\
\text { matter }\end{array}$} & \multirow[b]{2}{*}{ CEC $\ddagger$} & \multicolumn{3}{|c|}{ Soil texture } \\
\hline & & & & Sand & Silt & Clay \\
\hline & & $\mathrm{g} \mathrm{kg}^{-1}$ & $\mathrm{cmol}_{\mathrm{c}} \mathrm{kg}^{-1}$ & - & $-\%$ & - \\
\hline Bambey & 6.7 & 5.9 & 5.3 & 86 & 6 & 8 \\
\hline Thiès & 7.4 & 2.8 & 6.7 & 82 & 12 & 6 \\
\hline
\end{tabular}

and 20,000 hills per hectare for intercropped legumes. Planting patterns and densities are illustrated in Fig. 1.

Field trials were planted on 15 July in Thiès, and on 17 July in Bambey in 2013. In 2014, planting dates were 6 and 7 August for Bambey and Thiès, respectively. The growing season, from planting to harvest, was $82 \mathrm{~d}$ in 2013 and $79 \mathrm{~d}$ in 2014. Cowpea and mungbean seeds were inoculated prior to planting with appropriate rhizobacteria. The experimental sites had been left fallow the season prior and were disked before planting in 2013. Both sites were left untilled in 2014 and crops were planted manually into the previous year's crop residue. Between-row weeding was completed three times in the beginning of each season with a draft-powered cultivator and manually with a hoe. All crops were grown under rain-fed conditions with no fertilizer, insecticide, or herbicide inputs.

\section{Data Collection}

Millet was manually harvested from the two inside rows (4-m rows) of each plot, grain dried, and yields calculated based on $12.5 \%$ moisture content. Legume pods were left on the plant to dry and harvested from the five inside rows (4-m rows); each plant was harvested weekly until all mature pods were collected. Cowpea and mungbean grain yield calculations were also based on $12.5 \%$ moisture content. In addition to millet grain yield, the number of panicles per plot and average panicle length were measured and recorded at harvest.

Ground cover was calculated using overhead images taken every 2 wk with a remotely controlled, wide-angle digital camera on an adjustable 3-m camera stand. Images were processed using the supervised classification method in ERDAS Imagine (Hexagon Geospatial, Norcross, GA) to calculate percent ground cover. Ground cover included only living crop biomass,
Table 3. Experimental treatments and cultivars used in each treatment.

\begin{tabular}{|c|c|c|}
\hline No. & Treatment & Cultivar \\
\hline I. & Millet grown alone & Millet (ISMI-9507) \\
\hline 2. & $\begin{array}{l}\text { Millet-cowpea (viney) } \\
\text { intercrop }\end{array}$ & $\begin{array}{l}\text { Millet (ISMI-9507); } \\
\text { Cowpea (Melakh) }\end{array}$ \\
\hline 3. & $\begin{array}{l}\text { Millet-cowpea (upright) } \\
\text { intercrop }\end{array}$ & $\begin{array}{l}\text { Millet (ISMI-9507); } \\
\text { Cowpea (Yacine) }\end{array}$ \\
\hline 4. & $\begin{array}{l}\text { Millet-mungbean } \\
\text { (upright) intercrop }\end{array}$ & $\begin{array}{l}\text { Millet (ISMI-9507); } \\
\text { Mungbean (Berkens) }\end{array}$ \\
\hline 5. & Cowpea (viney) alone & Cowpea (Melakh) \\
\hline 6. & Cowpea (upright) alone & Cowpea (Yacine) \\
\hline 7. & Mungbean (upright) alone & Mungbean (Berkens) \\
\hline 8. & Millet alone with mulch & $\begin{array}{l}\text { Millet (ISMI-9507); Mulch } \\
\text { (Neem) }\end{array}$ \\
\hline
\end{tabular}

dry crop residues from the previous growing season (only present in Year 2), or mulch. Not all of the images were captured at an acceptable level for calculating ground cover percentage (certain images were tilted), and therefore only images from one block were used for each treatment. We realize that since there were no replications in this case that the data are not statistically reliable and are therefore presented for visual context only. Soil moisture readings were taken daily at a depth of 12 $\mathrm{cm}$ using a FieldScout TDR 100 soil moisture meter (Spectrum Technologies, Inc., Plainfield, IL). Three readings were randomly recorded from each plot in the two middle blocks. Only soil moisture data from the 2014 season are presented to account for the full effect of the previous season's crop residue. Normalized difference vegetation index readings were collected every $2 \mathrm{wk}$ in each plot to help determine $\mathrm{N}$ differences between treatments. Nitrogen content and chlorophyll are highly correlated and are reasonably quantifiable through light reflectance, specifically in the red and near infrared spectrums (Gamon et al., 1995). The NDVI was measured with a Trimble Greenseeker hand-held optical sensor (Trimble Navigation, Sunnyvale, CA). Millet and legume readings were measured separately when grown alone and when intercropped; readings were taken from individual rows rather than from an entire plot.

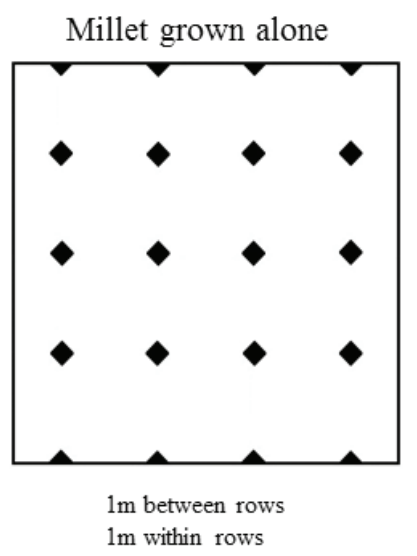

Legume grown alone

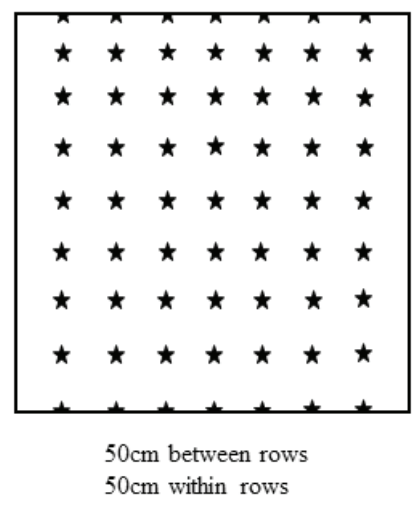

Millet-legume intercrop

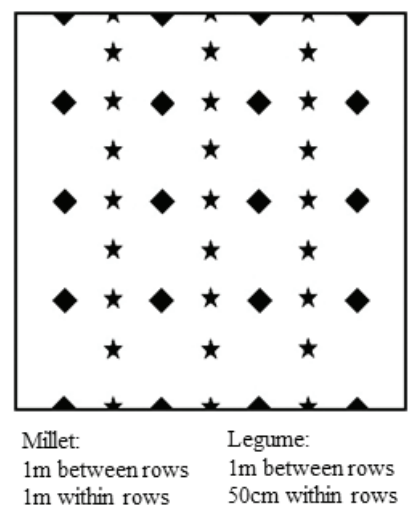

Fig. I. Planting arrangements for millet grown alone, cowpea and mungbean alone, and millet-legume intercropping treatments. 


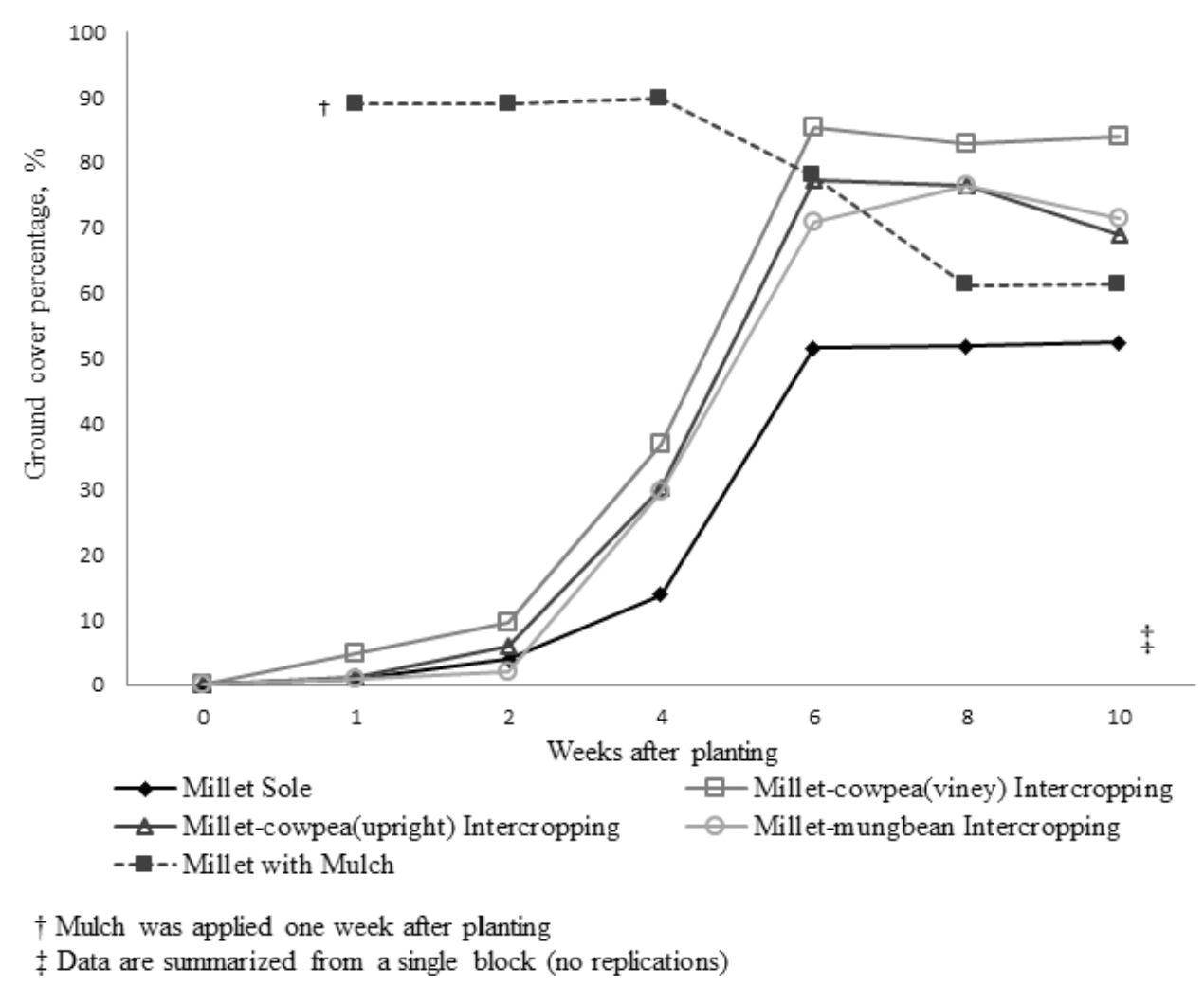

Fig. 2. Ground cover dynamics over time of millet grown alone, millet intercropped with two morphologically different cowpeas, millet intercropped with mungbean, and millet grown alone with mulch.
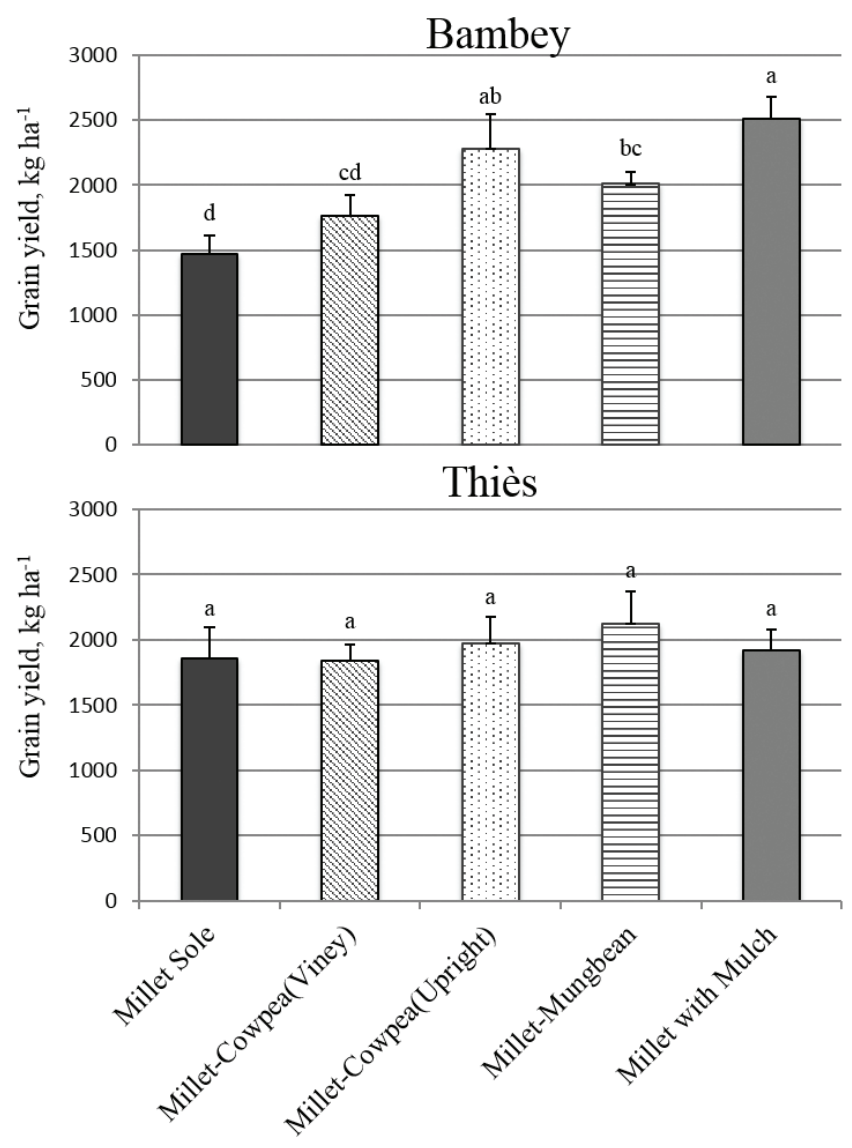

$\overline{\text { Fig. 3. Millet grain yield at Bambey and Thiès, averaged across } 2013}$ and 20I4. Treatments with the same letter are not significantly different according to Fisher's protected LSD $(\alpha=0.05)$ and error bars represent one standard error of the mean $(n=128)$.
Finally, yield data were used to calculate the land equivalency ratios (LERs) for each of the treatments. Land equivalency ratios are defined as the relative land area required for individual crops to attain the same yields as that of the intercropping combination of two or more crops grown in association (Willey and Osiru, 1972). The LER values were calculated as follows:

$$
\begin{gathered}
\text { Crop 1 } \\
\text { LER }=\left(\text { Yield }_{\text {intercrop }} / \text { Yield }_{\text {Sole }}\right)+\left(\text { Yield }_{\text {intercrop }} / \text { Yield }_{\text {Sole }}\right) \ldots
\end{gathered}
$$

when the LER = 1 there is no advantage to intercropping over growing either one of the crops on its own. Any LER > 1 indicates that intercropping is advantageous over individual cropping.

\section{Data Analysis}

Yields, along with soil moisture and NDVI, were analyzed with ANOVA using SAS JMP statistical software package (SAS Institute Inc., Cary, NC). Fisher's protected LSD ( $\alpha=$ 0.05 ) was used to separate differences among treatments. Plant population was used as a covariate in the analysis of legume yield data (ANCOVA) to account for plant population differences in individual plots. No significant differences were observed between years for NDVI, therefore results were combined across years.

\section{RESULTS Increased Ground Cover}

Intercropping and mulching resulted in increased ground cover compared to millet alone. (Fig. 2). The maximum ground cover percentage for millet alone reached $52 \% 6 \mathrm{wk}$ after planting, while the percent ground cover of millet intercropped with upright and viney legume cultivars was as high as 76 and $84 \%$, 
respectively. Ground cover of millet mulched with neem leaves was as high as $88 \%$ through the first 6 wk of planting and was only surpassed by the millet-legume intercropping treatments during the second half of the growing season.

\section{Millet, Legume, and Combined Intercropping Yields}

Despite the late onset of rains in 2014, yields did not vary significantly from year to year (Table 4). Rain fell consistently and produced adequate amounts of rainfall for two successful cropping seasons. The overall ANOVA is summarized in Table 4 , outlining the main effects and interactions of site, location, treatment, and block for all yield responses.

In Bambey, whenever millet was intercropped with a legume or grown with mulch, millet grain yields were higher than when millet was grown alone. Millet intercropped with the upright cowpea produced the highest of the intercropping treatments with a grain yield of $2279 \mathrm{~kg} \mathrm{ha}^{-1}$, which was a 55\% increase over millet grown alone (Fig. 3). Millet intercropped with the viney cowpea variety produced yields $20 \%$ higher than millet alone, while the millet intercropped with mungbean yielded 36\% more grain. Millet grown with mulch produced the greatest yield at $2510 \mathrm{~kg} \mathrm{ha}^{-1}$ of millet grain; an increase of $70 \%$ compared to millet grown alone (Fig. 3). Differences among treatments were not significant in Thiès, though yields only dropped below millet grown alone in one instance, when millet was intercropped with the viney cowpea cultivar.

Although millet yields increased in the intercropping treatments, the opposite was observed for the legume yield (Fig. 4). Intercropped legume yields were 30 to $50 \%$ of legumes grown alone. Most of these reductions in yield were the result of the decreased populations in intercropping treatments (Fig. 1).

Intercropping millet and legumes together always yielded more grain than millet or legumes alone. When millet was intercropped with the viney cowpea, the upright cowpea, or mungbean, there was higher overall grain production than millet or legumes alone. At both locations the three intercropping treatments produced more grain compared to the millet grown alone (not including the millet grown with mulch) (Fig. 5).

At Bambey, the millet-cowpea (upright) intercropping treatment produced more combined grain than millet intercropped with viney cowpea, with total grain production of $2461 \mathrm{~kg} \mathrm{ha}^{-1}$. The yield of this treatment was $67 \%$ higher than millet alone (Fig. 5). The millet-mungbean treatment yielded $43 \%$ more grain than millet alone. The lowest combined yield of the three intercropping treatments was the millet intercropped with the viney cowpea, which yielded $35 \%$ more than millet alone.

Although the effect of intercropping on the combined yield was evident at both locations, the combination of treatments that resulted in the highest yields differed between sites (Fig. 5). At Bambey, the combined yield of the millet and the upright cowpea was the highest of the intercropping treatments, while in Thiès combined yields were similar for the three intercropped treatments.

No statistical differences were found in the number of panicles between treatments in the first year at either site (Table 5). However, in the second year, the number of panicles was greater in the intercropping and mulching treatments, in comparison to that of the millet grown alone. In Bambey in 2014, where higher yields were observed in intercropping and mulched treatments, there were also higher numbers of panicles harvested. When panicle counts did not differ significantly between treatments, there was no significant difference between grain yields of these treatments either. In the second year of the study, at both Bambey and Thiès, the mulched treatments had the highest average number of panicles, as well as the highest overall yields. Differences in average panicle lengths changed only slightly between treatments.

\section{Soil Moisture}

Despite the increased ground cover provided by the cowpea and the mungbean, there was no significant increase in volumetric water content $\left(\mathrm{q}_{\mathrm{v}}\right)$ (data not shown) in intercropped millet compared to millet alone. However, the difference in seasonal mean $\mathrm{q}_{\mathrm{v}}$ between the millet with mulch and the millet alone was significant (Fig. 6). In Bambey, in 2014, the soil under the

Table 4. Analysis of variance of main effects and interactions of site, year, treatment, and block-millet, legume, and combined response.

\begin{tabular}{|c|c|c|c|c|c|c|c|}
\hline \multirow[b]{2}{*}{ Source } & \multirow[b]{2}{*}{$d f$} & \multicolumn{3}{|c|}{ Millet } & \multirow{2}{*}{$\begin{array}{l}\text { Legume } \\
\text { Bean yield }\end{array}$} & \multicolumn{2}{|c|}{ Combined } \\
\hline & & Millet yield & $\begin{array}{l}\text { Panicle } \\
\text { count }\end{array}$ & $\begin{array}{l}\text { Panicle } \\
\text { length }\end{array}$ & & $\begin{array}{c}\text { Combined } \\
\text { yield }\end{array}$ & $\begin{array}{c}\text { Land equivalency } \\
\text { ratio }\end{array}$ \\
\hline & & $\mathrm{kg} \mathrm{ha}^{-1}$ & per plot & $\mathrm{cm}$ & $\longrightarrow$ & 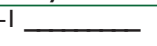 & \\
\hline Site & I & ns† & ns & ns & $* *$ & ns & $* *$ \\
\hline Year & I & ns & ns & $*$ & ns & ns & ns \\
\hline Treatment & 7 & $* * *$ & $* * *$ & $* * *$ & $* * *$ & $* * *$ & $* * *$ \\
\hline Site $\times$ Year & I & ns & $* *$ & ns & $* * *$ & ns & ns \\
\hline Site $\times$ Treatment & 7 & $*$ & ns & $*$ & $* * *$ & $* *$ & $* *$ \\
\hline Year $\times$ Treatment & 7 & ns & ns & ns & ns & ns & ns \\
\hline Site $\times$ Year $\times$ Treatment & 7 & ns & ns & ns & $*$ & ns & ns \\
\hline Block (Site × Year) & 12 & $* *$ & ns & ns & ns & $* * *$ & $* *$ \\
\hline Model & 43 & & & & & & \\
\hline Error & 84 & & & & & & \\
\hline Total & 127 & & & & & & \\
\hline
\end{tabular}

* Significant at $\alpha=0.05$.

** Significant at $\alpha=0.01$.

$* * *$ Significant at $\alpha=0.001$.

†ns- nonsignificant at $\alpha=0.05$. 
Bambey 2013
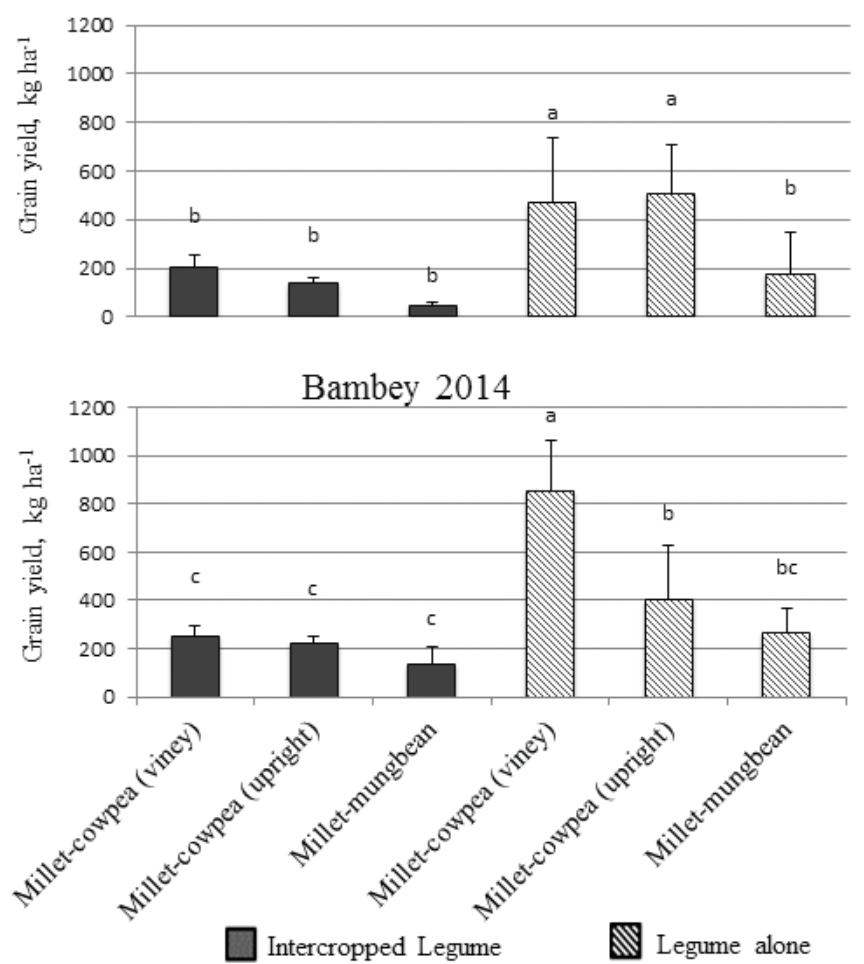

Thiès 2013

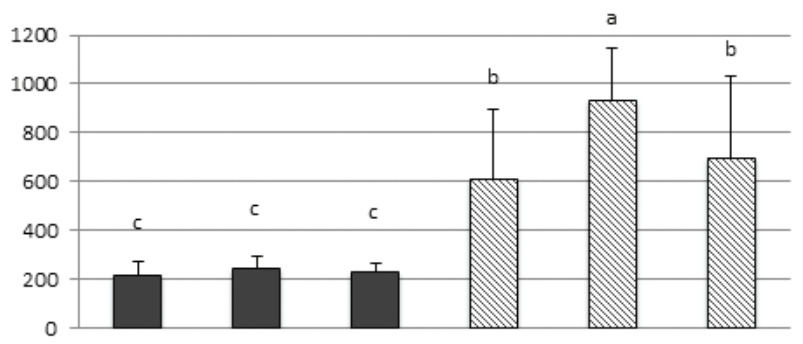

Thiès 2014

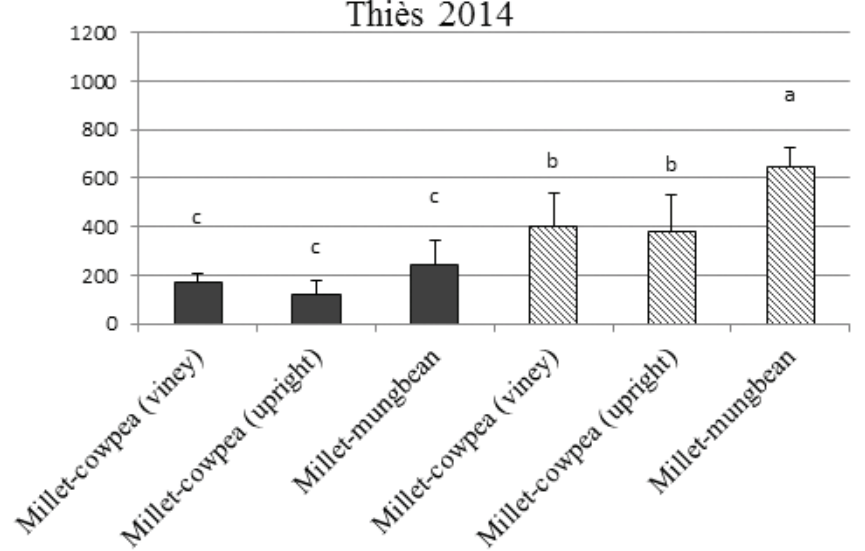

Fig. 4. Cowpea and mungbean grain yields when grown alone, and when intercropped with millet at Bambey and Thiès in 2013 and 2014. Treatments with the same letter are not significantly different according to Fisher's protected LSD $(\alpha=0.05)$ and error bars represent one standard error of the mean $(n=128)$.
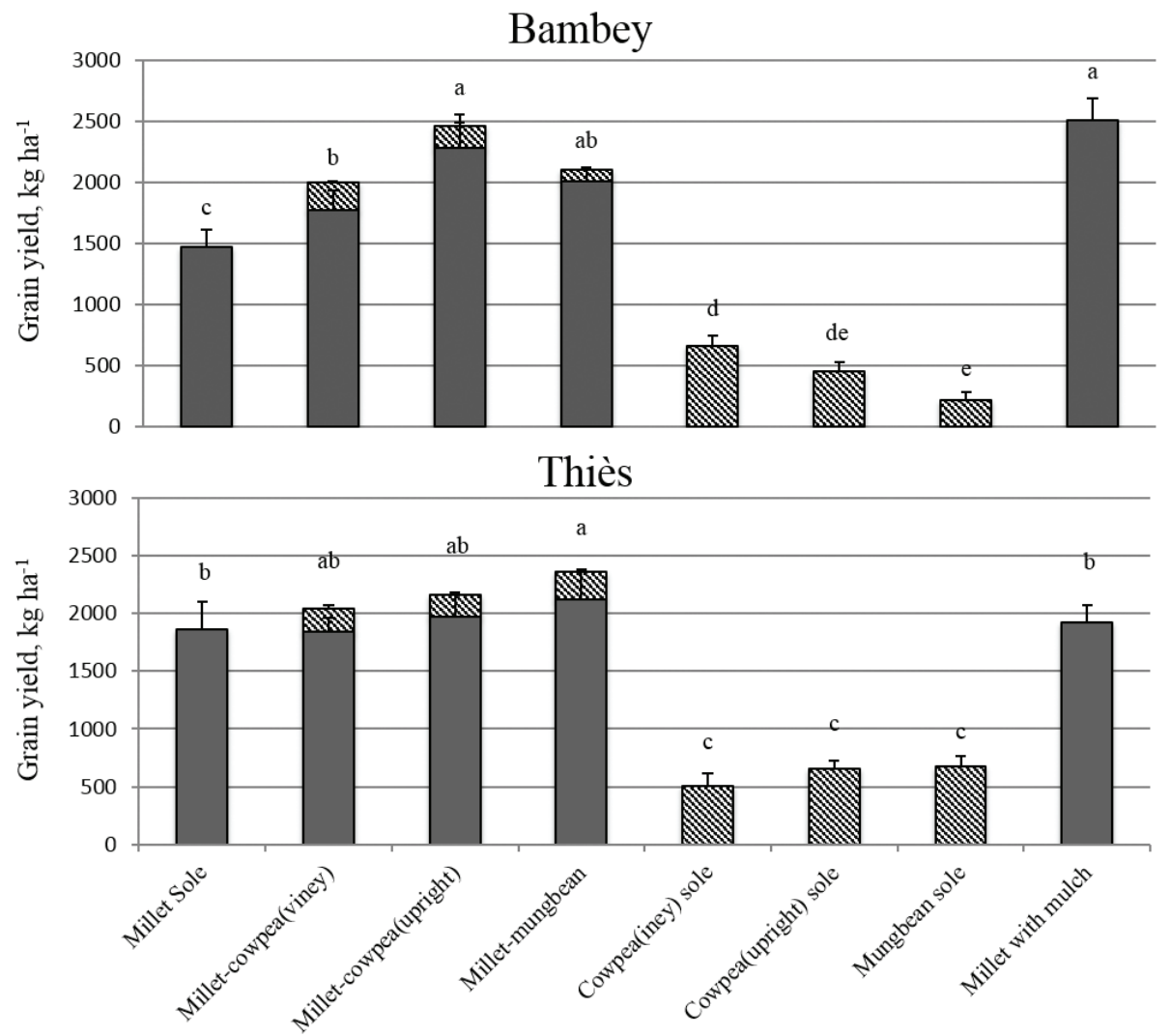

Millet $\mathbb{Q}$ Legume

Fig. 5. Combined grain yields (millet + legume) between treatments at the Bambey and Thiès locations-yields are averaged over the 2013 and 2014 growing seasons. Treatments with the same letter are not significantly different according to Fisher's protected LSD $(\alpha=0.05)$ and error bars represent one standard error of the mean $(n=128)$. 
Table 5. Millet panicle number and length by treatment at Bambey and Thiès for the 2013 and 2014 growing seasons.

\begin{tabular}{|c|c|c|c|c|c|c|}
\hline \multicolumn{2}{|c|}{ Year/site } & Millet sole & MCV Intercropt & MCU Intercrop $\ddagger$ & MM Intercrop§ & Millet + mulch \\
\hline & & \multicolumn{5}{|c|}{ Panicle count per plot } \\
\hline \multirow[t]{2}{*}{2013} & Bambey & $52 \mathrm{a} \|$ & $62 \mathrm{a}$ & $64 a$ & $56 a$ & $68 \mathrm{a}$ \\
\hline & Thiès & $50 \mathrm{a}$ & $4 l a$ & $52 a$ & $5 \mathrm{la}$ & $46 a$ \\
\hline \multirow[t]{3}{*}{2014} & Bambey & $44 b$ & $49 b$ & $58 \mathrm{ab}$ & $55 b$ & $67 a$ \\
\hline & Thiès & $57 b$ & $58 \mathrm{ab}$ & $52 b$ & $63 \mathrm{ab}$ & $69 \mathrm{a}$ \\
\hline & & \multicolumn{5}{|c|}{ Mean panicle length, $\mathrm{cm}$} \\
\hline \multirow[t]{2}{*}{2013} & Bambey & $40 \mathrm{a}$ & $37 c$ & $38 \mathrm{bc}$ & $39 b$ & $39 a b$ \\
\hline & Thiès & $38 b$ & $39 \mathrm{ab}$ & $40 a$ & $39 \mathrm{ab}$ & $38 b$ \\
\hline \multirow[t]{2}{*}{2014} & Bambey & $39 a$ & $38 a$ & $38 a$ & $39 a$ & $37 a$ \\
\hline & Thiès & $36 a b$ & $38 a b$ & $39 a$ & $37 a b$ & $37 b$ \\
\hline
\end{tabular}

† Millet-cowpea (viney) intercrop.

$\ddagger$ Millet-cowpea (upright) intercrop.

$\S$ Millet-mungbean intercrop.

TI Means within each row followed by the same letter are not significantly different at $\alpha=0.05$.
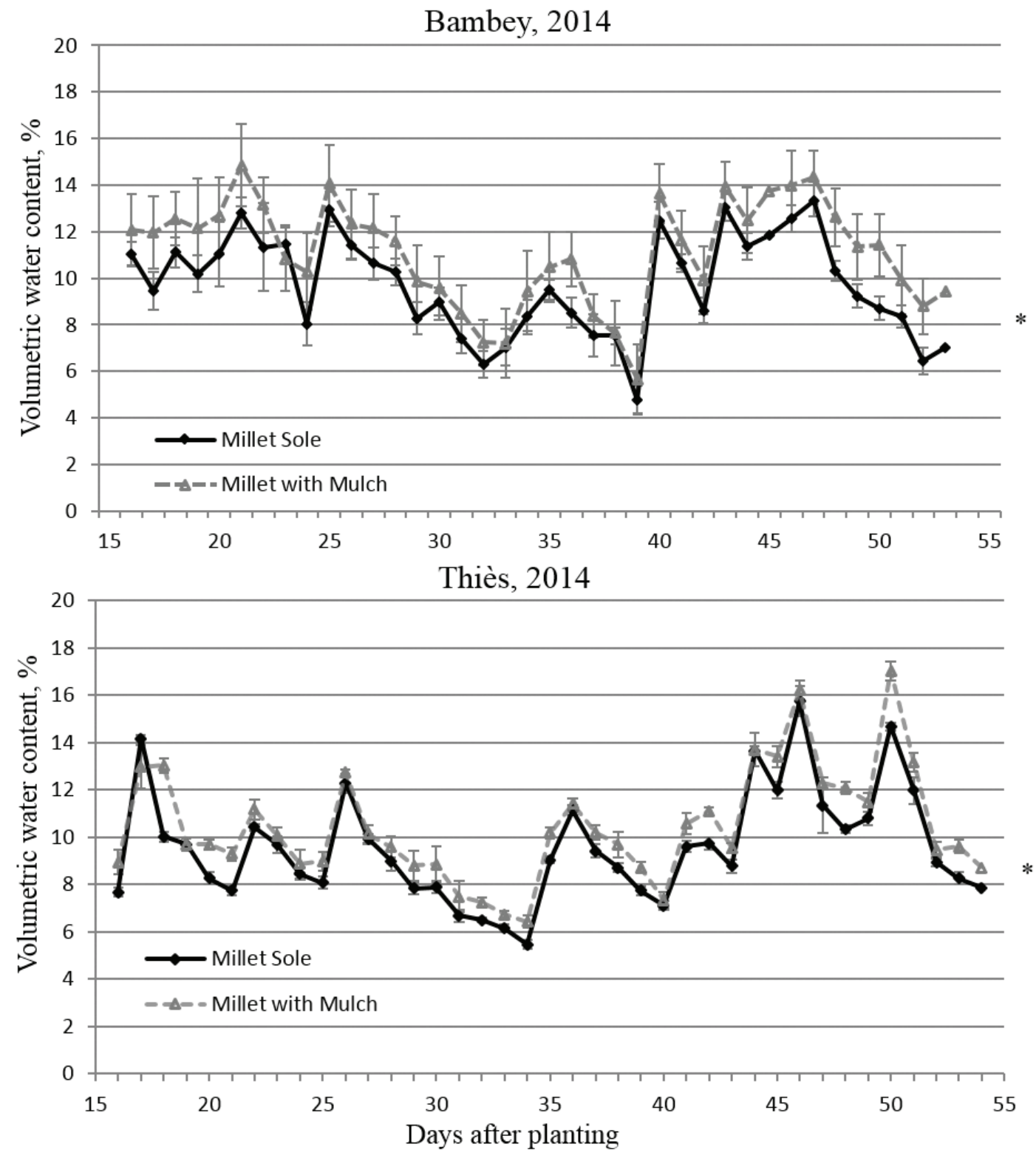

* - Average of the two lines is significantly different according to Fisher's protected LSD $(\alpha=0.05)$

Fig. 6. Soil volumetric water content (qv) measured at Bambey and Thiès during the 2014 growing season. Treatments noted with an asterisk are significantly different according to Fisher's protected LSD $(\alpha=0.05)$ and error bars represent one standard error of the mean $(n=128)$. 
Table 6. Land equivalency ratios for millet and legumes grown alone, and grown in association-values are averaged over the 2013 and 2014 growing seasons.

\begin{tabular}{|c|c|c|c|c|c|c|}
\hline \multirow[b]{3}{*}{ Cropping system } & \multicolumn{6}{|c|}{ Land equivalency ratio } \\
\hline & \multicolumn{3}{|c|}{ Bambey } & \multicolumn{3}{|c|}{ Thiès } \\
\hline & Millet & Legume & Overallt & Millet & Legume & Overallt \\
\hline Millet alone & 1.00 & - & $1.00 c$ & 1.00 & - & $1.00 \mathrm{~b}$ \\
\hline Millet-cowpea (viney) intercrop & 1.20 & 0.34 & $\mathrm{I} .54 \mathrm{~b}$ & 0.99 & 0.38 & $1.37 \mathrm{ab}$ \\
\hline Millet-cowpea (upright) intercrop & 1.55 & 0.40 & $1.95 \mathrm{a}$ & 1.06 & 0.28 & $1.34 \mathrm{ab}$ \\
\hline Millet-mungbean intercrop & 1.36 & $0.4 \mathrm{I}$ & $\mathrm{I} .77 \mathrm{ab}$ & 1.14 & 0.35 & $1.49 \mathrm{a}$ \\
\hline Millet with mulch & 1.70 & - & $\mathrm{I} .70 \mathrm{a}$ & 1.03 & - & $\mathrm{I} .03 \mathrm{~b}$ \\
\hline
\end{tabular}

$\dagger$ Means within each column followed by the same letter are not significantly different at $\alpha=0.05$.
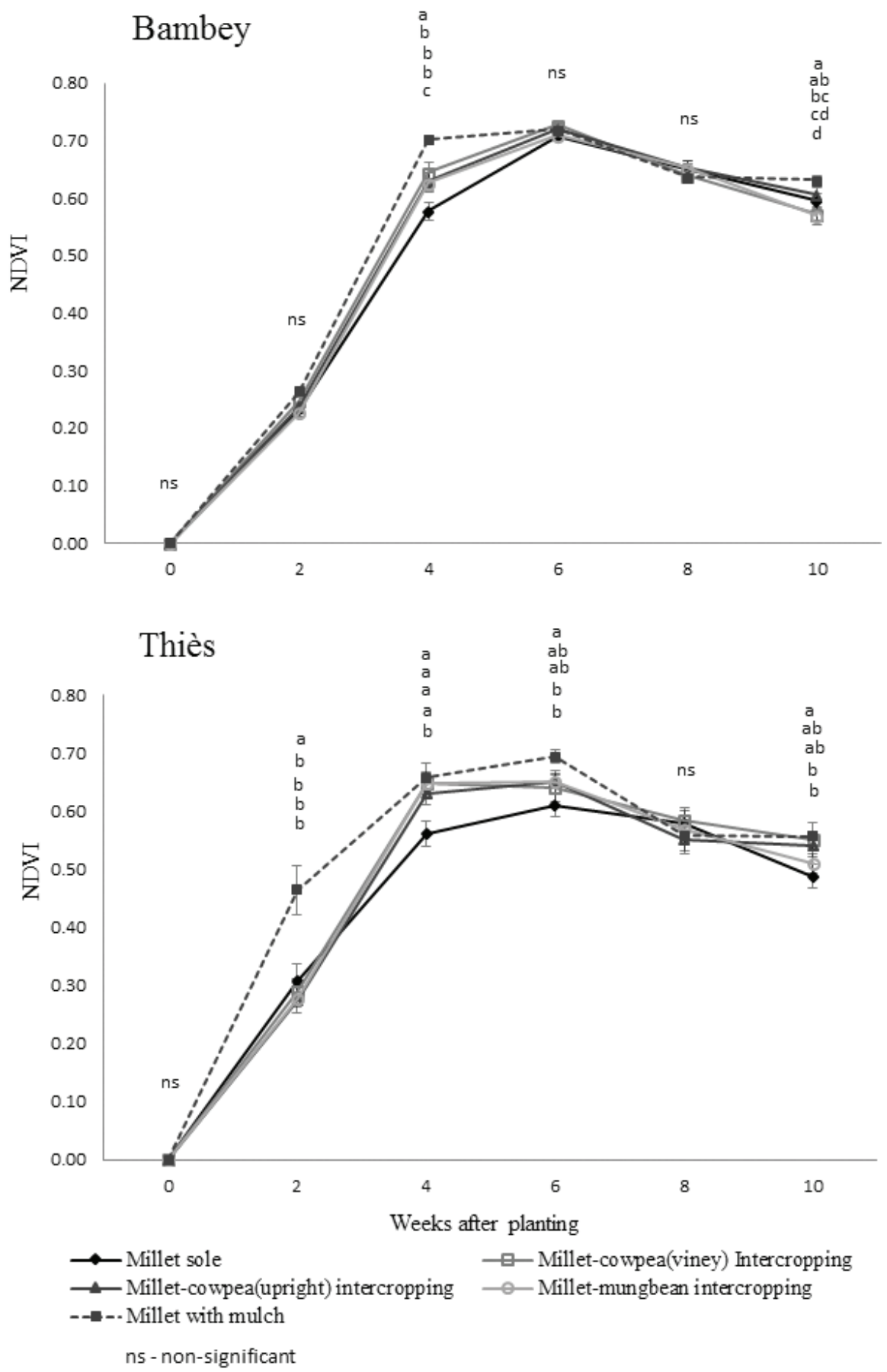

Fig. 7. Millet normalized difference vegetation index (NDVI) data from Bambey and Thiès, averaged across 20I3 and 20I4. Treatments with the same letter are not significantly different according to Fisher's protected LSD $(\alpha=0.05)$ and error bars represent one standard error of the mean $(n=128)$. 
mulched treatment had an average $\mathrm{q}_{\mathrm{v}}$ of $11.1 \%$ throughout the season, compared to $9.7 \%$ for millet grown without ground cover (Fig. 6). This represents a $14 \%$ increase in $\mathrm{q}_{\mathrm{v}}$ compared to millet alone, which is significantly higher $(P<0.05)$.

A similar trend was recorded at Thiès, where the mulched soils consistently retained more moisture than non-mulched soils (Fig. 6). During the 2014 growing season at Thiès, the mulched treatment had an average $\mathrm{q}_{\mathrm{v}}$ of $10.4 \%$ while the millet grown alone recorded an average of $9.6 \%$. This translates to an average increase in $\mathrm{q}_{\mathrm{v}}$ of $9 \%$, less than what was observed at Bambey, but a significant difference $(P<0.05)$ nonetheless.

\section{Normalized Difference Vegetation Index}

During the first 6 wk of growth, the NDVI data for each treatment followed the same trends as that of yield; with millet alone resulting in the empirically lowest values, followed by the three intercropping treatments, followed by the millet grown with mulch (Fig. 7). Four weeks after planting (prior to flowering), NDVI was $21 \%$ higher in millet grown with mulch, compared to the millet grown alone in Bambey. The NDVI in millet intercropped with cowpea and mungbean resulted in $9 \%$ higher NDVI on average for the three legume cultivars, compared to millet alone (Fig. 7). Similar results were recorded in Thiès at $4 \mathrm{wk}$, with mulched millet resulting in an $18 \%$ increase in NDVI, and intercropped NDVI increasing up to $16 \%$, compared to millet alone. After week 6, NDVI differences between treatments leveled out and exhibited no consistent treatment differences.

\section{Land Equivalency Ratios}

All of the intercropping treatments, at both sites, proved advantageous in terms of their LERs (ranging from 1.34-1.95). In both Bambey and Thiès, the LER for each of the three intercropping treatments was always $>1$, indicating that more yield was produced per unit of land in intercropping systems compared to millet or legumes grown alone on the same area. The LER's for the millet component of the millet-legume intercropping treatments ranged from 0.99 to 1.55 , while the legume component ranged from 0.28 to 0.41 (Table 6). The LER was also calculated for millet grown with mulch to illustrate potential advantages over growing millet with mulch; the LER in this case was 1.70 in Bambey and 1.03 in Thiès.

\section{DISCUSSION}

Millet yields increased when grown in association with cowpea or grown in association with mungbean. Reddy et al. (1992) reported increases in millet yields when similarly intercropped with cowpea in Niger. They reported a 14 to $15 \%$ yield increase in millet when it was intercropped with cowpea compared to when grown alone. Bationo et al. (1998) reported millet grains yields as high as $30 \%$ over millet alone. Other researchers have however reported decreases in millet yield when grown in association with legumes. Grema and Hess (1994) documented 34 and $23 \%$ yield reductions when millet was grown in association with two cowpea varieties (local and improved). A more recent study conducted in Senegal also showed lower yields of millet when intercropped with legumes, compared to millet grown alone (Diangar et al., 2004). The percentage yield decreases reported were 16 to $24 \%$ depending on the region (16\% in central-north vs. $24 \%$ in central-south) (Diangar et al., 2004).
The legumes grown in association with millet followed a similar declining trend, yielding lower than when they were grown alone. Reddy et al. (1992) reported that legume yields were reduced significantly when grown with millet compared to legumes grown alone. Similar to our results, the yield reductions reported for intercropped legumes were 36 and 48\% for Year 1 and 2, respectively.

The combined yields in our study were relatively high in comparison to other similar studies. We calculated LER's between 1.34 and 1.95, due primarily to the fact that millet benefitted from intercropping rather than competing with the legumes. Sarr et al. (2008) calculated an LER of 1.68 (in Senegal), while Reddy et al. (1992) calculated and LER of 1.48 (in Niger) in each of their millet-cowpea systems, respectively; Diangar et al. (2004) demonstrated an LER of 1.37 for millet-cowpea systems in Senegal's central south millet-peanut basin. It is difficult to compare these values as each study has unique planting densities and inputs.

The greatest yield increases in our study were observed in the treatments where millet was grown with mulch (up to $70 \%$ yield increase at Bambey). The increased millet yield associated with the mulch treatment can be attributed in part to higher soil moisture compared to when millet was intercropped or grown on its own. Though numerically small, the low $\mathrm{q}_{\mathrm{v}}$, percentage increases (2 to 3\%) prove to be critical in the sandy Sahelian soils where field capacity may only be as high as $15 \% \mathrm{q}_{\mathrm{v}}$.

Rebafka et al. (1994) found similar results in Niger using crop residues as mulch in millet fields. They compared the effects of short-term and long-term application of mulches and found that application of crop residues increased dry matter yields of pearl millet by $>60 \%$, while the omission of crop residues resulted in little to no improvement in yield (Rebafka et al., 1994). To examine the effect of mulch on soil moisture, Buerkert et al. (2000) conducted an experiment involving the addition of $2000 \mathrm{~kg} \mathrm{ha}^{-1}$ of mulch in three of West Africa's primary climatic zones (Sahelian, Sudanian, and Guinean). They reported increases in soil moisture content, specifically in the Sahel region (Buerkert et al., 2000). They found consistent increases in soil moisture levels in the 0 to $30 \mathrm{~cm}$ horizon over plots that were not treated with mulch. Mulumba and Lal (2008) analyzed soils under long-term (11 yr) mulch in Ohio and found an increase in available water of 18 to $35 \%$ in the upper $10 \mathrm{~cm}$ of the soil. While they used high rates of mulch $\left(8\right.$ and $\left.16 \mathrm{tha}^{-1}\right)$ in the experiment, they concluded that $2 \mathrm{t} \mathrm{ha}^{-1}$ of mulch (the same amount applied in our study) was enough to achieve $75 \%$ of these moisture retention rates (Mulumba and Lal, 2008).

Tilander and Bonzi (1997) demonstrated that using neem leaves as a mulch $\left(5 \mathrm{t} \mathrm{ha}^{-1}\right)$ in Burkina Faso increased sorghum yields up to $54 \%$ on average over 3 yr compared to the control grown without mulch. Results from their study also demonstrated that neem mulch significantly influenced soils by reducing soil temperatures and conserving soil moisture. They subsequently noted that soil organic matter was significantly improved over $3 \mathrm{yr}$, increasing from 0.41 to $0.90 \%$. They calculated the $\mathrm{N}$ content of their neem mulch to be $2.1 \%$, which if extrapolated to our application rate of $2 \mathrm{t} \mathrm{ha}^{-1}$, would result in a rough estimate of $42 \mathrm{~kg} \mathrm{~N} \mathrm{ha}^{-1}$ being brought into the field. This might help explain why in addition to high rates of soil moisture conservation, our NDVI were also higher in mulched millet compared to the treatments intercropped with cowpea or mungbean. 
In addition to increasing $\mathrm{q}_{\mathrm{v}}$, residues or mulches on the soil surface can provide other benefits, such as reducing the splasheffect of raindrops resulting in higher infiltration and reduced runoff, leading to less erosion. Though intercropped legumes may serve the same purpose in terms of erosion control, we hypothesize that any soil moisture saved through decreased moisture evaporation was subsequently lost to evapotranspiration of the growing crop. We found no significant increases in $\mathrm{q}_{\mathrm{v}}$ between intercropping treatments and sole cropping treatments. Though legumes may play a role in modifying water use and water sources in intercropping systems (Zegada-Lizarazu et al., 2005), we did not capture any significant soil moisture gains in intercropping treatments.

We conclude that our observed yield increases in millet in intercropping treatments (compared to the control), are likely a result of increased $\mathrm{N}$ availability. An assumption which is supported by higher NDVI values in every millet intercropping treatment compared to the millet that was grown alone, especially early on in the season. Research conducted in Niger by Laberge and Haussmann (2011) supports this hypothesis; they observed and quantified $\mathrm{N}$ transfer from the intercropped cowpea to the primary cereal crop (millet) at a rate of $1.4 \mathrm{~kg} \mathrm{~N} \mathrm{ha}^{-1}$ in millet grain. Planting arrangements and densities were similar to what were used in our trials. In conditions similar to these trials, where there are little to no $\mathrm{N}$ inputs (representative of many farmers in Senegal), any additional $\mathrm{N}$-even small quantities-may be crucial.

Various studies suggest that $\mathrm{N}$ transfer from legumes in cereal-legume rotations may be more beneficial than cereallegume intercropping (Bationo and Ntare, 2000; Laberge and Haussmann, 2011; Schlecht et al., 2006). It has been found that $\mathrm{N}$ pools from legumes grown prior to the cereal can impact plant growth, specifically earlier in the season (Laberge and Haussmann, 2011). We are confident that this was not the case with our early season increases, as neither of our fields had a legume grown on them the season prior to our trials. Nitrogen losses from cereal legume rotations may also be lost in early season rains through leaching, whereas $\mathrm{N}$ pools can be used more readily used when grown in association.

Although it was clear from our results that millet yields increased when intercropped with cowpea or mungbean, similar studies conducted in the region revealed millet yield declines when grown in association with a legume (Diangar et al., 2004; Grema and Hess, 1994; Ntare, 1990). To help understand why, we implemented a small field trial in Senegal in 2014 to evaluate our decision to inoculate our legume seeds, an additional step made over other trials with declining millet yields in intercropping systems. Results from this trial suggest inoculation of the cowpea and mungbean with appropriate rhizobacteria may have played a key role. Plants that received inoculation nearly doubled their number of root nodules compared to those without inoculation in both cowpea and mungbean (Trail, unpublished data, 2014). Replicated research is necessary to confirm these observations, but we believe that inoculation may have allowed for higher rates of $\mathrm{N}_{2}$ fixation than in some other studies. This increase in available $\mathrm{N}$, which is supported by our NDVI results, may have led to improved millet crop yield in the intercropping treatments, despite the higher plant populations and potential resource competition.

\section{CONCLUSIONS}

Increases in ground cover from intercropping and mulching were successfully quantified in this study, and each of these practices was proven to have beneficial potential in increasing yields. The three different intercropping systems evaluated in this study produced more grain per unit of land area than any of the millet or legume treatments grown alone. Our results showed that the inclusion of an intercropped legume, regardless of morphological characteristic or cultivar, often improved millet production and overall grain production. It is hard to say whether intercropping an upright cultivar or a viney cultivar is more beneficial, as our legume results were different across sites. The same can be said for cowpea vs. mungbean, no particular species clearly stood out as an all-round better choice.

Growing the millet under mulch proved to have the greatest benefit for millet yields. At Bambey where millet was grown under a layer of well-established mulch (neem leaves), there was an increase in millet grain yield over that of millet grown alone without the added ground cover. At the responsive site, mulched plots produced millet yield increases up to $70 \%$ over the untreated control.

In addition to quantifying the advantages of these different ground cover practices, we believe this work is important in that it has improved our understanding of the critical role of soil moisture conservation and $\mathrm{N}$ addition in desiccated (mulch) and living ground cover (legume intercropping). It was our hypothesis that intercropping yield advantages might come primarily from legume $\mathrm{N}_{2}$ fixation, while yield improvements from mulching practices might come primarily from soil moisture conservation. While this appears to be true for the intercropping practices, we conclude that improvements in soil moisture from mulching comes in conjunction with added $\mathrm{N}$ and organic matter from the mulch, even on early adoption of these practices $(<3 \mathrm{yr})$. These conclusions are in agreement with the findings of Tilander and Bonzi (1997) who found similar results. We found that these increases in millet yields were even high enough to outyield those of the combined millet-legume yields of the intercropping treatments in good conditions- demonstrated by an LER of 1.70 in the mulched treatment at Bambey-higher than any of the LER's calculated for the intercropping treatments.

It is also important to note that these field experiments were implemented without the use of fertilizers in an attempt to demonstrate that there are possible yield gains, even for the smallholder farmer who may lack the means to acquire external inputs. This research is by no means suggesting that fertilizers should not be applied, but rather is aimed at helping the farmer that may not have the luxury of obtaining fertilizers. By acquiring locally abundant neem leaves, or local legume seeds, the average smallholder farmer in Senegal may reasonably adopt mulching or intercropping practices, both of which have the potential to increase yields.

\section{ACKNOWLEDGMENTS}

This work was made possible by the U.S. Agency for International Development and the generous support of the American people. We would like to extend a special thank you to the hardworking staff members of the Education and Research in Agriculture (ERA) project in Senegal, as well as those from the ENSA and ISFAR agricultural institutions. We would like to also acknowledge the contributions of the Virginia Tech Office of International Research, Education, and Development (OIRED) and those in the Department of Crop and Soil Environmental Sciences. 


\section{REFERENCES}

Bationo, A., F. Lompo, and S. Koala. 1998. Research on nutrient flows and balances in west Africa: State-of-the-art. Agric. Ecosyst. Environ. 71:19-35. doi:10.1016/S0167-8809(98)00129-7

Bationo, A., and B.R. Ntare. 2000. Rotation and nitrogen fertilizer effects on pearl millet, cowpea and groundnut yield and soil chemical properties in a sandy soil in the semi-arid tropics, West Africa. J. Agric. Sci. 134:277-284. doi:10.1017/S0021859699007650

Buerkert, A., A. Bationo, and K. Dossa. 2000. Mechanisms of residue mulch-induced cereal growth increases in West Africa. Soil Sci. Soc. Am. J. 64:346-358. doi:10.2136/sssaj2000.641346x

Climate Research Unit of East Anglia. 2014. Average monthly temperature and rainfall for Senegal at location $(14.72,-16.61)$ from 1990-2009. The World Bank Group, Climate Change Knowledge Portal. http://sdwebx.worldbank.org/climateportal/index. cfm?page $=$ country_historical_climate $\&$ ThisRegion $=$ Africa $\& \mathrm{~T}$ hisCCode $=$ SEN (accessed 17 Nov. 2014).

Diangar, S., A. Fofana, M. Diagne, C.F. Yamoah, and R.P. Dick. 2004. Pearl millet-based intercropping systems in the semiarid areas of Senegal. Afr. Crop Sci. J. 12:133-139. doi:10.4314/acsj. v12i2.27671

FAOSTAT. 2013. Average millet yields in Senegal compared to West Africa and India. United Nations Food and Agriculture Organization-Div. of Statistics. http://faostat3.fao.org/download/Q/ QC/E (accessed 10 Feb. 2015.)

Fofana, B., M.C.S. Wopereis, A. Bationo, H. Breman, and A. Mando. 2008. Millet nutrient use efficiency as affected by natural soil fertility, mineral fertilizer use and rainfall in the West African Sahel. Nutr. Cycling Agroecosyst. 81:25-36 doi:10.1007/ s10705-007-9146-y.

Fussell, L.K., M.C. Klaij, C. Renard, and B. N’Tare. 1989. Millet based production systems for improving food production in the southern Sahelian zone. Farming Systems Research Workshop on Appropriate Technologies for Achieving Sustainable Food Production Systems in Semi-Arid Africa. Ouagadougou, Burkina Faso.

Gamon, J.A., C.B. Field, M.L. Goulden, K.L. Griffin, A.E. Hartley, G. Joel, J. Peñuelas, and R. Valentini. 1995. Relationships between NDVI, canopy structure, and photosynthesis in three Californian vegetation types. Ecol. Appl. 5:28-41. doi:10.2307/1942049

Grema, A.K., and T.M. Hess. 1994. Water balance and water use of pearl millet-cowpea intercrops in north east Nigeria. Agric. Water Manage. 26:169-185. doi:10.1016/0378-3774(94)90056-6
Laberge, G., and B.I.G. Haussmann. 2011. Cowpea N rhizodeposition and its below-ground transfer to a co-exsisting and subsequent millet crop on a sandy soil of the Sudano-Sahelian eco-zone. Plant Soil 340:369-382. doi:10.1007/s11104-010-0609-6

Lahmar, R., B.A. Bationo, N. Dan Lamso, Y. Guéro, and P. Tittonell. 2012. Tailoring conservation agriculture technologies to West Africa semi-arid zones: Building on traditional local practices for soil restoration. Field Crops Res. 132:158-167. doi:10.1016/j. fcr.2011.09.013

Mulumba, L.N., and R. Lal. 2008. Mulching effects on selected soil physical properties. Soil Tillage Res. 98:106-111. doi:10.1016/j. still.2007.10.011

Ntare, B.R. 1990. Intercropping morphologically different cowpeas with pearl millet in a short season environment in the Sahel. Exp. Agric. 26:41-47. doi:10.1017/S0014479700015386

Rebafka, F.P., A. Hebel, A. Bationo, K. Stahr, and H. Marschner. 1994. Short- and long-term effects of crop residues and of phosphorus fertilization on pearl millet yield on an acid sandy soil in Niger, West Africa. Field Crops Res. 36:113-124. doi:10.1016/0378-4290(94)90060-4

Reddy, K.C., P. Visser, and P. Buckner. 1992. Pearl millet and cowpea yields in sole and intercrop systems, and their after-effects on soil and crop productivity. Field Crops Res. 28:315-326. doi:10.1016/0378-4290(92)90017-4

Sarr, P.S., M. Khouma, M. Sene, A. Guisse, A.N. Badiane, and T. Yamahawa. 2008. Effect of pearl millet-cowpea cropping systems on nitrogen recovery, nitrogen use efficiency, and biological fixation using the ${ }^{15} \mathrm{~N}$ tracer technique. Soil Sci. Plant Nutr. 54:142-147. doi:10.1111/j.1747-0765.2007.00216.x

Schlecht, E., A. Buerkert, E. Tielkes, and A. Bationo. 2006. A critical anlysis of challenges and opportunities for soil fertility restoraion in Sudano-Sahelian West Africa. Nutr. Cycling Agroecosyst. 79:109-136.

Stoskopf, N.C. 1985. Pearl millet. Cereal grain crops. Reston Publ. Company, Inc., Reston, VA. p. 429-444.

Tilander, Y., and M. Bonzi. 1997. Water and nutrient conservation through the use of agroforestry mulches, and sorghum yield response. Plant Soil 197:219-232. doi:10.1023/A:1004263930096

Willey, R.W., and D.S. Osiru. 1972. Studes on mixture of maize and beans (Phaseolus vulgaris) with particular reference to plant population. J. Agric. Sci. (Camb.) 79:517-529. doi:10.1017/S0021859600025909

Zegada-Lizarazu, W., S. Niitembu, and M. Iijima. 2005. Mixed planting with legumes modified the water source and water use of pearl millet. Plant Prod. Sci. 8(4): 433:440. doi:10.1626/pps.8.433 